\title{
Correction to: Ethical Sensitivity of Nursing Students During a 4-Year Nursing Curriculum in Turkey
}

\author{
Hilal Gamze Hakbilen $^{1}$ (D) Serpil Ince ${ }^{1}$ (D) . Mustafa Levent Ozgonul ${ }^{2}$ (D)
}

Published online: 8 November 2021

(c) Springer Nature B.V. 2021

\section{Correction to: Journal of Academic Ethics https://doi.org/10.1007/s10805-021-09432-2}

The original version of this article unfortunately contained a mistake in the affiliation section. Authors Hilal Gamze Hakbilen and Serpil İnce should be under the Department of Fundamentals of Nursing, while Mustafa Levent Ozgonul is with the Department of Medical History and Ethics. The updated affiliation is shown below.

The original article has been corrected.

Publisher's Note Springer Nature remains neutral with regard to jurisdictional claims Sin published maps and institutional affiliations.

The original article can be found online at https://doi.org/10.1007/s10805-021-09432-2.

Hilal Gamze Hakbilen

Serpil Ince

serpildogan@akdeniz.edu.tr

Mustafa Levent Ozgonul

leventozgonul@akdeniz.edu.tr

1 Department of Fundamentals of Nursing, Akdeniz University Faculty of Nursing, Antalya, Turkey

2 Department of Medical History and Ethics, Akdeniz University Faculty of Medicine, Antalya, Turkey 